http://jmscr.igmpublication.org/home/ ISSN (e)-2347-176x ISSN (p) 2455-0450 crossref DOI: https://dx.doi.org/10.18535/jmscr/v7i12.125

\title{
A Study of Pattern of Adverse Transfusion Reactions to Blood Components in a Tertiary Care Teaching Hospital: A Prospective Observational Study
}

Authors

\author{
Dr Sujeet A. Divhare* Dr Satyashil Ingale, Dr Mohit Upadhye \\ Department of Pharmacology, B.J. Government Medical College, Pune \\ *Corresponding Author \\ Dr Sujeet A. Divhare \\ Assistant Professor, Department of Pharmacology, B.J. Government Medical College, Pune
}

\begin{abstract}
Background: In this modern era, hemovigilance has emerged as a branch of pharmacovigilance that checks the occurrence \& recurrence of reactions to blood and blood derived products and provides guidelines for their prevention.

Aim and Objectives: In this study, we have attempted to understand the pattern of Adverse Transfusion Reactions (ATRs) to different blood components according to genders, blood groups \& blood components; to propose a model for the study of the same and to find out the incidence of such reactions.

Material and Methods: The study was carried out in a tertiary care teaching hospital. We prospectively observed transfusion of 892 units of different blood components to 445 patients over a period of 30 days: average 2 transfusions per patient \& 29.73 transfusions per day. Patients showing various adverse reactions to transfusion of these blood components were analyzed with a questionnaire specially designed, taking the reference of Suspected Adverse Drug Reaction Reporting Form (CDSCO).

Results: We observed that the overall incidence of ATRs in 892 transfusions is $5.27 \%$ ( $p=0.05$ ). Both, women and men, are equally affected. A+ve, $B+v e \& O+v e$ are the blood groups frequently showing transfusion reactions. O+ve blood group shows higher susceptibility than B+ve blood group. Patients having a past history of blood transfusions are particularly susceptible to develop adverse reactions to further transfusions. The main culprits of these reactions are Fresh Frozen Plasma(FFP), Human Red Blood Cells (HRBC), Single Wash Human Red Blood Cells (SWHRBC) with the incidence being highest for FFP and lowest for SWHRBC. Acute Febrile Reactions are the most commonly encountered reactions followed in frequency by dyspnoea \& orthopnoea with acute hemolytic reactions being a rarity due to stringent precautions. We also noted a case of Transfusion associated Acute Lung Injury (TRALI) and two cases of skin rashes. We have documented certain odd reactions whose references could not be found in the literature.

Conclusion: Most commonly encountered reactions were Acute Febrile Reactions followed in frequency by dyspnoea and orthopnoea. Acute Hemolytic Reactions and Transfusion associated Acute Lung Injury (TRALI) were rare events. We have been able to propose a model for the study of pattern of such reactions. With proper use of this model we conclude that the susceptibility of a particular blood group in a particular gender to a particular blood component can be found out. There can be an underestimation of the true incidence of transfusion reactions because of underreporting which can be improved by hemovigilance system.

Keywords: Hemovigilance, Acute Transfusion Reactions, Blood groups, Blood components.
\end{abstract}




\section{Introduction}

The $17^{\text {th }}$ century was blessed with the discovery of blood circulation by Sir William Harvey that shed the light upon the importance of blood and aroused a substantial interest in its use as a drug for therapeutic purposes. The earliest documentation of use of blood was for the rejuvenation of youth in sick and elderly with the blood of healthy and young! In 1666 Sir Richard Lower and Sir Edmund King carried out the first successful blood transfusion in humans. Dr. James Blundell, in 1818, saved many lives from postpartum hemorrhage with transfusion of blood. Though blood transfusion can be life-saving, it can also lead to certain adverse reactions which can be fatal. ${ }^{[1]}$ There is limited high-quality evidence of the benefits and harms of different blood product transfusion practices that exist throughout the world. ${ }^{[2]}$ Knowledge about various types of blood transfusion reactions will help not only in their early identification and management, but also in taking adequate measures to prevent the same. The true incidence of these reactions is difficult to determine because of lack of a proper and strict hemovigilance system throughout the country.

In this modern scientific age, hemovigilance has become an established process of continuous data collection and analysis of transfusion related adverse reactions in order to investigate their causes and outcomes and prevent their occurrence or recurrence. The rationale is to increase the safety and efficacy of blood transfusion covering all the activities of the transfusion chain from donor to recipient.

To further the work, we aimed at studying the pattern of Adverse Transfusion Reactions (ATRs) according to genders, blood groups \& blood components; to propose an appropriate model for the study of the same and to find out their incidence. As it is well established that the use of separate blood components for specific indications is superior in efficacy and safety than the transfusion of whole blood (with exceptions), we closely monitored the transfusions of the components like Fresh Frozen Plasma (FFP), Human Red Blood Cells (HRBC), Single Wash Human Red Blood Cells (SWHRBC), Platelets \& Cryoprecipitate and documented the observed reactions in a specially designed format to find out results to our objectives.

\section{Material and Methods}

The study was carried out in a tertiary care teaching hospital from Western Maharashtra (India) after getting the approval of Institutional Ethics Committee. We enrolled the patients of all age groups and of either gender from all departments (including pediatric age groups and women admitted in antenatal care wards). The components undertaken for surveillance were Human Red Blood Cells (HRBC), Platelet Rich Plasma (PRP) or simply Platelets, Fresh Frozen Plasma (FFP) and Cryoprecipitate. We prospectively observed transfusion of 892 units of different blood components to 445 patients over a period of 30 days: average 2 transfusions per patient \& 29.73 transfusions per day. Patients showing various adverse reactions to transfusion of these blood components were analyzed with a questionnaire specially designed, taking the reference of Suspected Adverse Drug Reaction Reporting Form (CDSCO). Strict confidentiality of the prescriber and the patient was maintained.

\section{Results}

We came to observe 47 reactions occurring in 445 patients: incidence being $10.56 \%$ [Table 1]. The overall incidence of Adverse Transfusion Reactions in 892 transfusions is $5.27 \%(\mathrm{p}=0.05)$. 33 out of 47 patients $(70.21 \%)$ showing reactions had a past history of blood transfusion.

Out of 236 females 26 showed reactions: incidence being $11 \%$ ( $\mathrm{p}=0.11$ ). Out of 209 males 21 showed reactions: incidence being $10.04 \%$ (0.10) [Figure1]. We find the difference between the incidences of females and males not significant by applying Chi square test (Chi square $=0.532<3.84$ at $\mathrm{p}=0.05$ ). 
Table 1: Distribution according to gender of patients

\begin{tabular}{|l|c|c|c|}
\hline & No. of Reactions & No. of Patients in sample & Percentage (\%) \\
\hline Females & 26 & 236 & 11 \\
\hline Males & 21 & 209 & 10.04 \\
\hline Total & 47 & 445 & 10.56 \\
\hline
\end{tabular}

Figure 1: Sample size and reaction trends

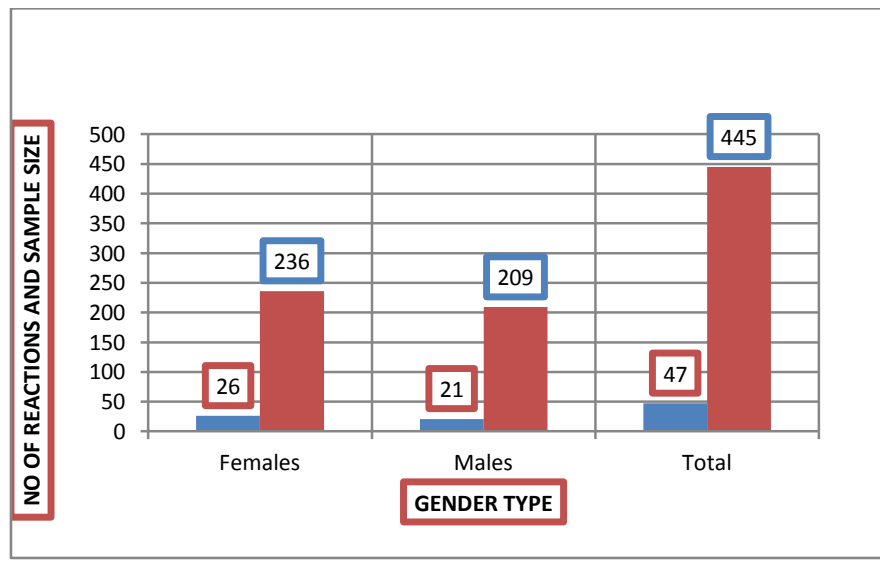

The blood groups that showed reactions were $\mathrm{A}+\mathrm{ve}, \mathrm{B}+\mathrm{ve}, \mathrm{O}+\mathrm{ve}, \mathrm{AB}+\mathrm{ve}$, and $\mathrm{O}-\mathrm{ve}$ [Figure 2]. Taking into consideration the sample strength of each blood group, patients of $\mathrm{O}+\mathrm{ve}, \mathrm{A}+\mathrm{ve} \& \mathrm{~B}+\mathrm{ve}$ blood groups showed significant number of reactions, their Incidences being $12.59 \%, 15.15 \%$,
$7.95 \% \quad(\mathrm{p}=0.1259,0.1515,0.795)$ respectively [Table 2]. There is a significant difference between the incidences of $\mathrm{O}+\mathrm{ve} \& \mathrm{~B}+\mathrm{ve}$ groups (with comparable sample strength): Group O+ve showing higher incidence.

Table 2: Distribution according to blood groups

\begin{tabular}{|l|c|c|c|}
\hline Blood Groups & No. of Reactions & No. of Units in sample & Percentage (\%) \\
\hline O+ & 17 & 135 & $12.59 \%^{*}$ \\
\hline A+ & 15 & 99 & $15.15 \%$ \\
\hline B+ & 12 & 151 & $7.95 \% *$ \\
\hline AB+ & 2 & 43 & $4.65 \%$ \\
\hline O- & 1 & 7 & $14.28 \%$ \\
\hline
\end{tabular}

Figure 2: Blood group and reactions

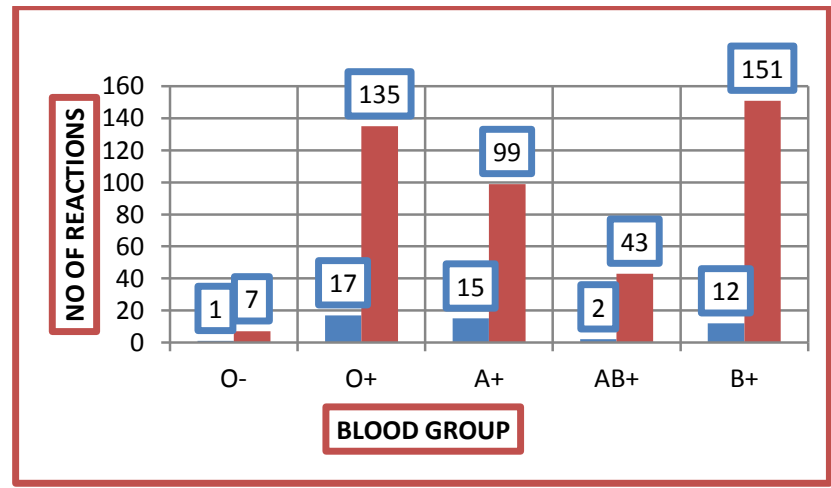

From the commonly transfused components: FFP, HRBC \& SWHRBC showed frequent reactions their incidences being $12.98 \%, 10.62 \% \& 7.59 \%$ respectively [Table 3]. Maximum number of reactions is shown by FFP. Also with their comparable sample strengths FFP shows a higher Incidence of reactions than SWHRBC. 
Table 3: Distribution according to blood components

\begin{tabular}{|l|c|c|c|}
\hline Blood Component & No. of Reactions & No. of Units in sample & Percentage (\%) \\
\hline CRYO & 1 & 3 & $33 \%$ \\
\hline FFP & 10 & 77 & $12.98 \% *$ \\
\hline HRBC & 29 & 273 & $10.62 \%$ \\
\hline SWHRBC & 6 & 79 & $7.59 \%^{*}$ \\
\hline PLT & 1 & 13 & $7.69 \%$ \\
\hline
\end{tabular}

Figure 3: Blood components and reactions

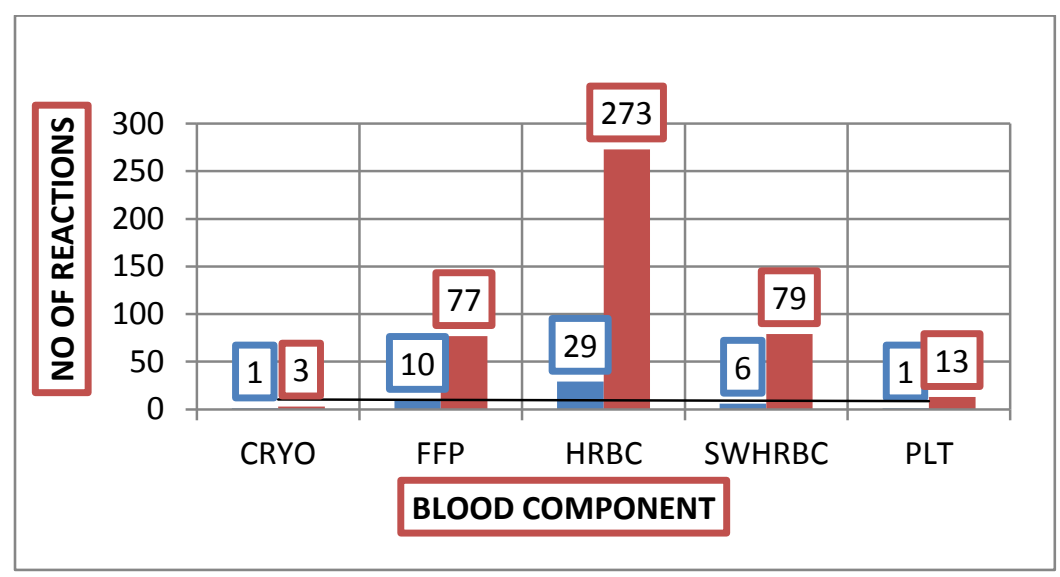

In females, $\mathrm{O}+\mathrm{ve}, \mathrm{A}+\mathrm{ve} \& \mathrm{~B}+\mathrm{ve}$ are the blood groups showing significant number of reactions: Their incidences being $16.21 \%, 12.96 \%$ \& $5.40 \%$ respectively [Table 4]. O+ve blood group shows significantly higher incidence than $\mathrm{B}+\mathrm{ve}$ group considering their equal sample strength (74 patients each).

Table 4: Distribution according to Blood Groups in females

\begin{tabular}{|l|c|c|c|}
\hline Blood Groups & No. of Reactions & No. of patients in sample & Percentage (\%) \\
\hline A+ & 7 & 54 & $12.96 \%$ \\
\hline B+ & 4 & 74 & $5.40 \%$ \\
\hline O+ & 12 & 74 & $16.21 \%$ \\
\hline AB+ & 1 & 23 & $4.34 \%$ \\
\hline O- & 1 & 5 & $20 \%$ \\
\hline
\end{tabular}

Figure 4: Distribution according to Blood Groups in females

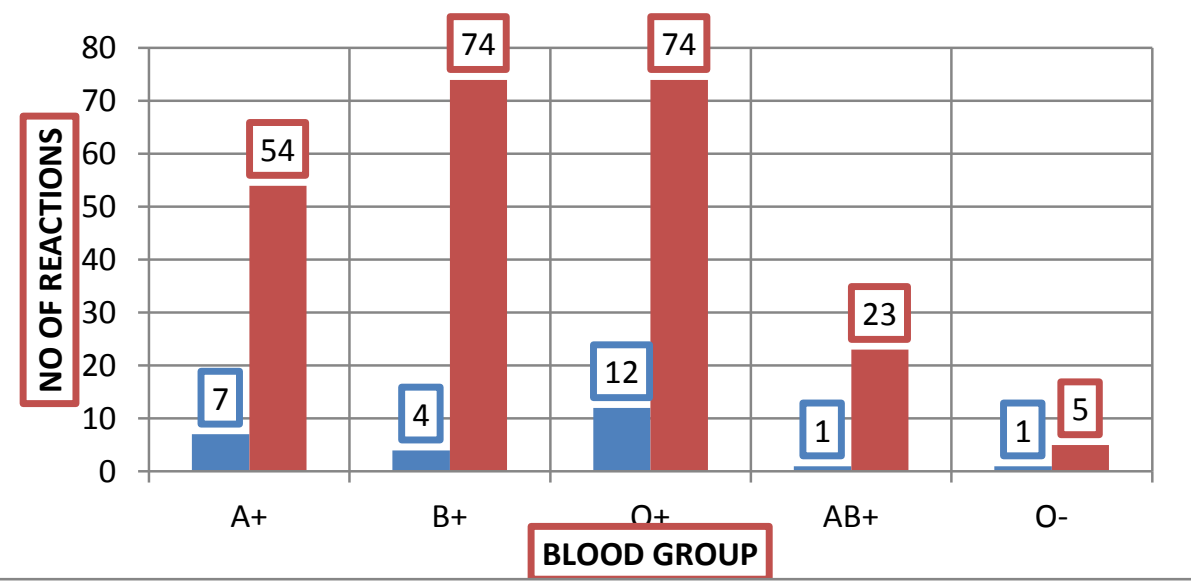

In males, $\mathrm{O}+\mathrm{ve}, \mathrm{A}+\mathrm{ve} \& \mathrm{~B}+\mathrm{ve}$ are the blood groups showing significant number of reactions: their incidences being $6.56 \%, 15.55 \%$ \& $10.25 \%$. [Table 5] 
Table 5: Distribution according to blood groups in males

\begin{tabular}{|l|c|c|c|}
\hline Blood Groups & $\begin{array}{c}\text { No. of } \\
\text { Reactions }\end{array}$ & $\begin{array}{c}\text { No. of Patients in } \\
\text { sample }\end{array}$ & Percentage (\%) \\
\hline $\mathrm{A}+$ & 7 & 45 & $15.55 \%$ \\
\hline $\mathrm{B}+$ & 8 & 78 & $10.25 \%$ \\
\hline $\mathrm{O}+$ & 4 & 61 & $6.56 \%$ \\
\hline $\mathrm{AB}+$ & 1 & 20 & $5 \%$ \\
\hline
\end{tabular}

Figure 5: Distribution according to blood groups in males

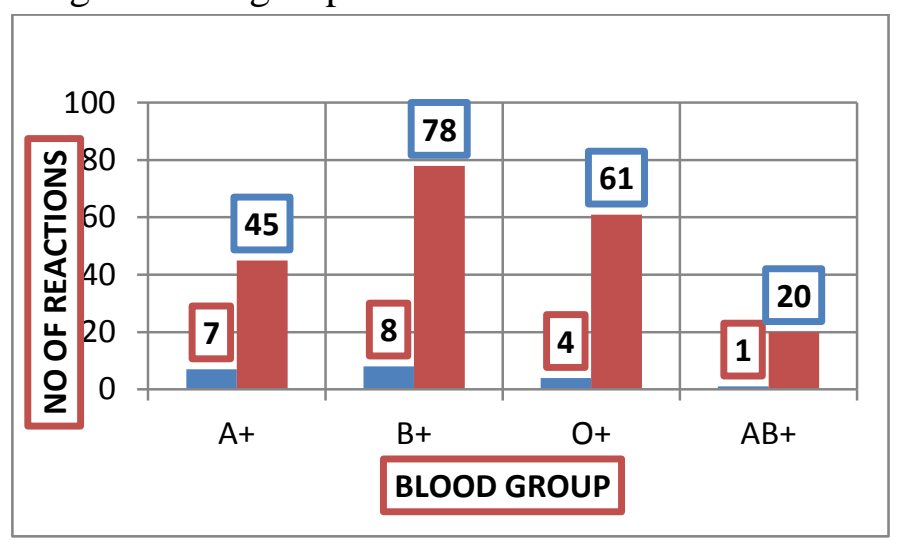

Table $7 \& 8$ gives the distribution of incidences of Adverse Transfusion Reactions according to Gender, Blood groups and Blood components. Our findings suggest that males of blood groups
$\mathrm{B}+\mathrm{ve} \& \mathrm{O}+\mathrm{ve}$ and Females of blood groups $\mathrm{A}+\mathrm{ve}$, $\mathrm{B}+\mathrm{ve} \& \mathrm{O}+\mathrm{ve}$ show significant susceptibility to developing reactions with $\mathrm{HRBC}$.

Table 7: Distribution according to Genders (males), Blood groups \& Blood products

\begin{tabular}{|l|c|c|c|c|c|c|c|c|}
\hline & $\begin{array}{c}\text { MR A+ve/ } \\
\text { M A+ve }\end{array}$ & $\begin{array}{c}\text { MR B+ve/ } \\
\text { M B+ve }\end{array}$ & $\begin{array}{c}\text { MR O+ve/ } \\
\text { M O+ve }\end{array}$ & $\begin{array}{c}\text { MR AB+ve/ } \\
\text { M AB+ve }\end{array}$ & $\begin{array}{c}\text { MR A-ve / } \\
\text { M A-ve }\end{array}$ & $\begin{array}{c}\text { MR B-ve/ } \\
\text { M B-ve }\end{array}$ & $\begin{array}{c}\text { MR O-ve/ } \\
\text { M O-ve }\end{array}$ & $\begin{array}{c}\text { MR AB-ve/ } \\
\text { M AB-ve }\end{array}$ \\
\hline FFP & $6 / 9$, & $0 / 18$, & $0 / 7$, & $0 / 4$, & $0 / 0$, & $0 / 0$, & $0 / 0$, & $0 / 0$, \\
\hline HRBC & $\mathbf{6 6 . 6 7 \%}$ & $0 \%$ & $0 \%$ & $0 \%$ & $0 \%$ & $0 \%$ & $0 \%$ & $0 \%$ \\
& $0 / 29$, & $8 / 47$, & $2 / 37$, & $1 / 7$ & $0 / 0$, & $0 / 1$, & $0 / 1$, & $0 / 2$, \\
\hline PLT & $0 \%$ & $\mathbf{1 7 . 0 2 \%}$ & $\mathbf{7 . 4 0 \%}$ & $\mathbf{1 4 . 2 8 \%}$ & $0 \%$ & $0 \%$ & $0 \%$ & $0 \%$ \\
\hline SWHRBC & $0 / 1$, & $0 / 2$, & $0 / 1$, & $0 / 0$ & $0 / 0$, & $0 / 0$, & $0 / 0$, & $0 / 0$, \\
& $0 \%$ & $0 \%$ & $0 \%$ & $0 \%$ & $0 \%$ & $0 \%$ & $0 \%$ & $0 \%$ \\
\hline CRYO & $0 / 6$, & $0 / 11$, & $2 / 15$, & $0 / 9$ & $0 / 0$, & $0 / 0$, & $0 / 0$, & $0 / 0$, \\
& $0 \%$ & $0 \%$ & $\mathbf{1 3 . 3 3 \%}$ & $0 \%$ & $0 \%$ & $0 \%$ & $0 \%$ & $0 \%$ \\
\hline
\end{tabular}

$[\mathrm{PLT}=$ Platelets, MR=Males showing reactions, $\mathrm{FR}=$ Females showing reactions, $\mathrm{M}=$ Total number of males in the sample, $\mathrm{F}=$ Total number of females in the sample, Corresponding blood group is written in the front.]

Table 8: Distribution according to Genders (females), Blood groups \& Blood products

\begin{tabular}{|l|c|c|c|c|c|c|c|c|}
\hline & $\begin{array}{c}\text { FR A+ve/ F } \\
\text { A+ve }\end{array}$ & $\begin{array}{c}\text { FR B+ve/ F } \\
\text { B+ve }\end{array}$ & $\begin{array}{c}\text { FR O+ve/ } \\
\text { F O+ve }\end{array}$ & $\begin{array}{c}\text { FR AB+ve/ F } \\
\text { AB+ve }\end{array}$ & $\begin{array}{c}\text { FR A-ve / } \\
\text { F A-ve }\end{array}$ & $\begin{array}{c}\text { FR B-ve/ } \\
\text { F B-ve }\end{array}$ & $\begin{array}{c}\text { FR O-ve/ } \\
\text { F O-ve }\end{array}$ & $\begin{array}{c}\text { FR AB-ve/ } \\
\text { F AB-ve }\end{array}$ \\
\hline FFP & $2 / 13$, & $0 / 11$, & $2 / 9$, & $0 / 6$, & $0 / 0$, & $0 / 0$, & $0 / 0$, & $0 / 0$, \\
& $\mathbf{1 5 . 3 8 \%}$ & $0 \%$ & $\mathbf{2 2 . 2 2 \%}$ & $0 \%$ & $0 \%$ & $0 \%$ & $0 \%$ & $0 \%$ \\
\hline HRBC & $5 / 31$, & $2 / 46$, & $9 / 51$, & $1 / 12$ & $0 / 1$, & $0 / 2$, & $1 / 3$, & $0 / 2$, \\
& $\mathbf{1 6 . 1 3 \%}$ & $\mathbf{4 . 3 5 \%}$ & $\mathbf{1 7 . 6 5 \%}$ & $\mathbf{8 . 3 3 \%}$ & $0 \%$ & $0 \%$ & $\mathbf{3 3 . 3 3 \%}$ & $0 \%$ \\
\hline PLT & $1 / 4$, & $0 / 2$, & $0 / 2$, & $0 / 1$ & $0 / 0$, & $0 / 0$, & $0 / 0$, & $0 / 0$, \\
& $\mathbf{2 5 \%}$ & $0 \%$ & $0 \%$ & $0 \%$ & $0 \%$ & $0 \%$ & $0 \%$ & $0 \%$ \\
\hline SWHRBC & $0 / 6$, & $2 / 14$, & $2 / 12$, & $0 / 4$ & $0 / 0$, & $0 / 0$, & $0 / 2$, & $0 / 0$, \\
& $0 \%$ & $\mathbf{1 4 . 2 9 \%}$ & $\mathbf{1 6 . 6 7 \%}$ & $0 \%$ & $0 \%$ & $0 \%$ & $0 \%$ & $0 \%$ \\
\hline CRYO & $0 / 1$, & $0 / 0$, & $0 / 0$, & $0 / 0$ & $0 / 0$, & $0 / 0$, & $0 / 0$, & $0 / 0$, \\
& $0 \%$ & $0 \%$ & $0 \%$ & $0 \%$ & $0 \%$ & $0 \%$ & $0 \%$ & $0 \%$ \\
\hline
\end{tabular}


Out of 47 reactions we studied: 29 were Acute Febrile Reactions (61.7\%), 8 had dyspnoea or orthopnoea as a prominent feature $(17.02 \% \%), 2$ were confirmed Acute Hemolytic Reactions
(4.26\%), 1 was Transfusion associated Acute Lung Injury (TRALI) (2.13\%), 2 reactions evolved with skin rash $(4.26 \%)$.

Table 9: Percentage distribution of Transfusion reactions

\begin{tabular}{|l|c|c|}
\hline & Number & Percentage (\%) \\
\hline Acute Febrile Reactions & 29 & $3.2 \%$ \\
\hline Dyspnoea or Orthopnoea & 8 & $0.8 \%$ \\
\hline Acute Hemolytic Reactions & 2 & $0.2 \%$ \\
\hline TRALI & 1 & $0.1 \%$ \\
\hline Skin rash & 2 & $0.2 \%$ \\
\hline Other & 5 & $0.5 \%$ \\
\hline Total & 47 & \\
\hline
\end{tabular}

\section{Discussion}

In the present study, information about various adverse transfusion reactions was collected from cases reported to the blood bank of the tertiary care teaching hospital. These were then evaluated on the basis of demographic details of the patients, their clinical history, blood groups and various blood products transfused using a pre-defined protocol. In the present study, the overall incidence of adverse transfusion reactions in 892 transfusions is $5.27 \%(\mathrm{p}=0.05)$. Both women and men are equally affected. $\mathrm{A}+\mathrm{ve}, \mathrm{B}+\mathrm{ve}, \mathrm{O}+\mathrm{ve}$ are the blood groups frequently showing transfusion reactions. O+ve blood group shows higher susceptibility than $\mathrm{B}+\mathrm{ve}$ blood group. In women the higher susceptibility of $\mathrm{O}+\mathrm{ve}$ than $\mathrm{B}+\mathrm{ve}$ blood group is clearly seen. FFP, HRBC \& SWHRBC are frequently involved in the reactions. The order according the incidences: FFP $>\mathrm{HRBC}>$ SWHRBC. Men of blood groups $\mathrm{B}+\mathrm{ve} \& \mathrm{O}+\mathrm{ve}$ and Women of blood groups $\mathrm{A}+\mathrm{ve}, \mathrm{B}+\mathrm{ve} \& \mathrm{O}+\mathrm{ve}$ show significant susceptibility to developing reactions with $\mathrm{HRBC}$.

In a similar study by Bhattacharya et al., incidence of adverse transfusion reaction was $0.18 \%$. ${ }^{[3]}$

The total number of adverse reactions in various studies may not be the actual indicator mainly because of under reporting. Under reporting of minor adverse transfusion reactions has also been found by Narvios et al. ${ }^{[4]}$
In the present study, the frequency of acute haemolytic reactions (non-immune) was found to be $0.2 \%$. The frequency of acute hemolytic reactions observed in different studies ranges from 0.2 to 0.7 per 1,000 red cell units transfused. ${ }^{[5]}$ In all the acute haemolytic reactions reported, hemolytic reaction was confirmed by hemoglobinuria, hematuria and rise of serum unconjugated bilirubin. All of these patients had received anti-human globulin negative blood products. These adverse transfusion reactions were attributed to non-immune causes like thermal injury as a result of storage in the unmonitored domestic refrigerator in the ward or due to rapid transfusion through fine bored IV cannulas that was used to transfuse hypotonic intravenous fluids simultaneously. It has been observed that PRBC with a hematocrit of $75-80 \%$, when transfused forcibly through 21-22G IV cannula may result in local hemolysis. ${ }^{[6]}$ Improper storage conditions and inappropriate rate or method of transfusion leads to deterioration of blood products. Hence, it is prudent to educate the nursing staff and medical residents to reduce this risk. There are a lot of variations in the frequency of acute febrile reactions among different studies throughout the world. This can be attributed to the variations in reporting system, frequent use of antipyretics and antihistaminics, and pretransfusion condition of the patient. ${ }^{[7]}$ In our study, the frequency of acute febrile reactions is $3.2 \%$. TRALI is a rare, but important cause of 
transfusion-related mortality. ${ }^{[8]}$ It is a great mimicker of a variety of clinical conditions and can be life threatening. In our study, the frequency of TRALI is $0.1 \%$. However, the donor sample could not be evaluated for anti-HLA or anti-HNA antibodies which may suggest susceptible host factors. Careful selection of donors can decrease incidence of TRALI. ${ }^{[9]}$

A short duration of the study limits the sample strength hence firm conclusions regarding such patterns could not be drawn. Studying the age wise distribution of the reactions was out of the scope of this study. Only the acute reactions were undertaken for scrutiny.

\section{Conclusion}

The frequency of ATRs in our patients was found to be $5.27 \%$. The majority of the types of reactions observed were acute febrile reactions. Despite vigorous donor screening, bacterial contamination still remains an important cause of transfusion-related morbidity and mortality. The sources of these bacteria are often from donor either from venepuncture site or breach in the aseptic technique during component preparation and storage. There can be an underestimation of the true incidence of transfusion reactions because of underreporting which can be improved by hemovigilance system. Resident doctors and nurses in the ward should understand the importance of reporting all major and minor transfusion events to the blood bank. There lays a grave concern regarding the underreporting of adverse reactions due to transfusion of blood and blood products. Our goal of safe transfusion can be achieved only by establishing a efficient hemovigilance system.

\section{Conflict of interest: None.}

\section{References}

1. Sharma S, Sharma P, Tyler LN. Transfusion of blood and blood products:
Indications and complications. Am Fam Physician. 2011;83:719-24.

2. Carson JL, Grossman BJ, Kleinman S, Tinmouth AT, Marques MB, Fung MK, et al. Red blood cell transfusion: A clinical practice guideline from the AABB ${ }^{*}$. Ann Intern Med. 2012;157:49-58.

3. Bhattacharya P, Marwaha N, Dhawan HK, Roy P, Sharma RR. Transfusion-related adverse events at the tertiary care center in North India: An institutional hemovigilance effort. Asian J Transfus Sci. 2011;5:164-70.

4. Narvios AB, Lichtiger B, Neumann JL. Underreporting of minor transfusion reactions in cancer patients. Med Gen Med. 2004;6:17.

5. Uhlmann EJ, Isgriggs E, Wallhermfechtel M, Goodnough LT. Prestorage universal WBC reduction of $\mathrm{RBC}$ units does not affect the incidence of transfusion reactions. Transfusion. 2001;41:997-1000.

6. Beauregard P, Blajchman MA. Hemolytic and pseudo-hemolytic transfusion reactions: An overview of the hemolytic transfusion reactions and the clinical conditions that mimic them. Transfus Med Rev. 1994;8:184-99.

7. Praveen Kumar, Rakesh Thapliyal, Poonam Coshic, and Kabita Chatterjee. Retrospective evaluation of adverse transfusion reactions following blood product transfusion from a tertiary care hospital: A preliminary step towards hemovigilance. Asian J Transfus Sci. 2013 Jul-Dec; 7(2): 109-115.

8. Webert KE, Blajchman MA. Transfusionrelated acute lung injury. Transfus Med Rev. 2003;17:252-62.

9. Popovsky MA, Chaplin HC, Jr, Moore SB. Transfusion-related acute lung injury: A neglected, serious complication of hemotherapy. Transfusion. 1992; 32:58992. 